\title{
Ortaokul Öğrencilerinin Okuma Kaygılarının Çeşitli Değişkenler Bakımından İncelenmesi
}

\author{
Hüseyin Çevik ${ }^{1}$, Şenol Orakcı ${ }^{2},{\text { Osman } \mathrm{Aktan}^{3} \text {, Çetin Toraman }}^{4}$ \\ ${ }^{1}$ Milli Ĕgitim Bakanlı̆̆ı, Öğretmen, Türkiye \\ ${ }^{2}$ Aksaray Üniversitesi Eğitim Fakültesi, Dr. Öğr. Üyesi, Aksaray, Türkiye \\ ${ }^{3}$ Milli Ĕgitim Bakanlı̆̆l, Dr. Öğretmen, Türkiye \\ ${ }^{4}$ Çanakkale Onsekiz Mart Üniversitesi Tıp Fakültesi, Dr. Öğr. Üyesi, Çanakkale, Türkiye
}

Sorumlu Yazar: Osman Aktan, karakteregitimi@gmail.com

Makale Türü: Araştırma Makalesi

Kaynak Gösterimi: Çevik, H., Orakcı, Ş., Aktan, O., \& Toraman, Ç. (2019). Ortaokul öğrencilerinin okuma kaygılarının çeşitli değişkenler bakımından incelenmesi. Eğitimde Kuram ve Uygulama, 15(1), 1-16. doi: 10.17244/eku.398683

\section{Examination of Middle School Students' Reading Anxiety in Terms of Various Variables}

\author{
Hüseyin Çevik ${ }^{1}$, Şenol Orakcı ${ }^{2}$, Osman $\mathrm{Aktan}^{3}$, Çetin Toraman ${ }^{4}$ \\ ${ }^{1}$ Ministry of Education, Turkey \\ ${ }^{2}$ Faculty of Education, Aksaray University, Aksaray, Turkey \\ ${ }^{3}$ Ministry of Education, Turkey \\ ${ }^{4}$ Faculty of Medicine, Çanakkale Onsekiz Mart University, Çanakkale, Turkey
}

Corresponding Author: Osman Aktan, karakteregitimi@gmail.com

Article Type: Research Article

To Cite This Article: Çevik, H., Orakcı, Ş., Aktan, O., \& Toraman, Ç. (2019). Ortaokul öğrencilerinin okuma kaygılarının çeşitli değişkenler bakımından incelenmesi. Eğitimde Kuram ve Uygulama, 15(1), 1-16. doi: 10.17244/eku.398683 


\title{
Ortaokul Öğrencilerinin Okuma Kaygılarının Çeşitli Değişkenler Bakımından İncelenmesi
}

\author{
Hüseyin Çevik ${ }^{1}$, Şenol Orakcı ${ }^{2}$, Osman Aktan ${ }^{3}$, Çetin Toraman ${ }^{4}$ \\ ${ }^{1}$ Milli Ĕ̌gitim Bakanlı̆̆l, Ögretmen \\ ORCID: http://orcid.org/0000-0003-8420-5481 \\ ${ }^{2}$ Aksaray Üniversitesi Ĕ̆itim Fakültesi, Dr. Öğr. Üyesi, Aksaray, Türkiye \\ ORCID: http://orcid.org/0000-0003-1534-1310

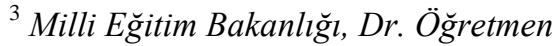 \\ ORCID: http://orcid.org/0000-0001-6583-3765 \\ ${ }^{4}$ Çanakkale Onsekiz Mart Üniversitesi Tıp Fakültesi, Dr. Öğr. Üyesi, Çanakkale, Türkiye \\ ORCID: http://orcid.org/0000-0001-5319-0731
}

\begin{tabular}{|c|c|}
\hline$\ddot{O} z$ & Makale Bilgisi \\
\hline $\begin{array}{l}\text { Bu araştırmanın amacı Ankara ili, Keçiören ilçesinde öğrenim gören ortaokul } \\
\text { öğrencilerinin okuma kaygılarının çeşitli değişkenler bağlamında incelenmesidir. } \\
\text { Araştırma ilişkisel tarama deseninde gerçekleştirilmiştir. Araştırmada Ankara ili Keçiören } \\
\text { ilçesinde bulunan okullarda öğrenim gören, veri toplaması kolay, gönüllülük ilkesiyle } \\
\text { araştırmaya katılan } 368 \text { ortaokul öğrencisi araştırma grubunu oluşturmuştur. Araştırmada } \\
\text { veri toplama aracı olarak Melanlığlu (2014) tarafından geliştirilmiş olan "Okuma } \\
\text { Kaygısı Ölçeği (OKÖ) kullanılmıştır. Verilerin analizinde IBM-SPSS } 22 \text { programı } \\
\text { kullanılmıştır. Verilerin normal dağılım göstermemesi nedeniyle analizler Spearman } \\
\text { Brown Sıra Farkları Korelasyon Katsayısı, Mann Whitney U Test, Kruskal Wallis Test } \\
\text { gibi non-parametrik teknikler ile yapılmıştır. Araştırma bulguları incelendiğinde, } \\
\text { katılımcıların okuma kaygısı ölçeği alt boyutları incelendiğinde katılımcıların okuma } \\
\text { sürecini planlama ve okumayı destekleyen unsurlar alt boyutlarında düşük puanlara } \\
\text { yığıldıkları okuduğunu anlama ve çözümleme boyutunda ise ortanın üzerinde puan } \\
\text { aldıkları belirlenmiştir. Türkçe dersi akademik başarı düzeyi ile gerek okuma kaygısı } \\
\text { ölçeğinin toplam puanı ve gerekse alt boyutlarının hiçbiri ile anlamlı bir ilişki olmadığ1 } \\
\text { belirlenmiştir. Araştırma bulgularına dayalı olarak cinsiyete, aile gelir düzeyine ve } \\
\text { öğrencilerin en son ne zaman kitap okuduğuna göre okuma kaygısının boyutlarında } \\
\text { anlamlı farklılık olmadığı belirlenmiştir. Hem anne ve hem de baba eğitim durumuna göre } \\
\text { göre okuma kaygısı ölçeğinin sadece "okuduğunu anlama ve çözümleme” alt boyutunda } \\
\text { anlamlı farklılık tespit edilmiş olup, diğer boyutlarda anne ve baba eğitim düzeyine göre } \\
\text { anlamlı farklılık belirlenmemiştir. Anne ve babanın evde kitap okuma durumuna göre } \\
\text { okuma sürecini planlama, okuduğunu anlama ve çözümleme boyutlarında anlamlı bir } \\
\text { farklılık belirlenmiş olup, okumayı destekleyen unsurlar alt boyutu ile okuma kaygısı } \\
\text { toplam puanlarında anlamlı farklılık belirlenmemiştir. Araştırma bulgularına dayalı olarak } \\
\text { okuma kaygısını azaltmaya yönelik eğitsel çalışmalar düzenlenmesi ve rehberlik } \\
\text { yapılması önerilmiştir. }\end{array}$ & $\begin{array}{l}\text { Anahtar Kelimeler: Başarı, } \\
\text { Dil öğretimi, Okuma kaygısı } \\
\text { Makale Geçmişi: } \\
\text { Geliş: } 26 \text { Şubat } 2018 \\
\text { Düzeltme: } 12 \text { Nisan } 2018 \\
\text { Kabul: } 27 \text { Kasım } 2018\end{array}$ \\
\hline
\end{tabular}




\section{Examination of Middle School Students' Reading Anxiety in Terms of Various Variables}

\begin{tabular}{|c|c|}
\hline Abstract & Article Info \\
\hline 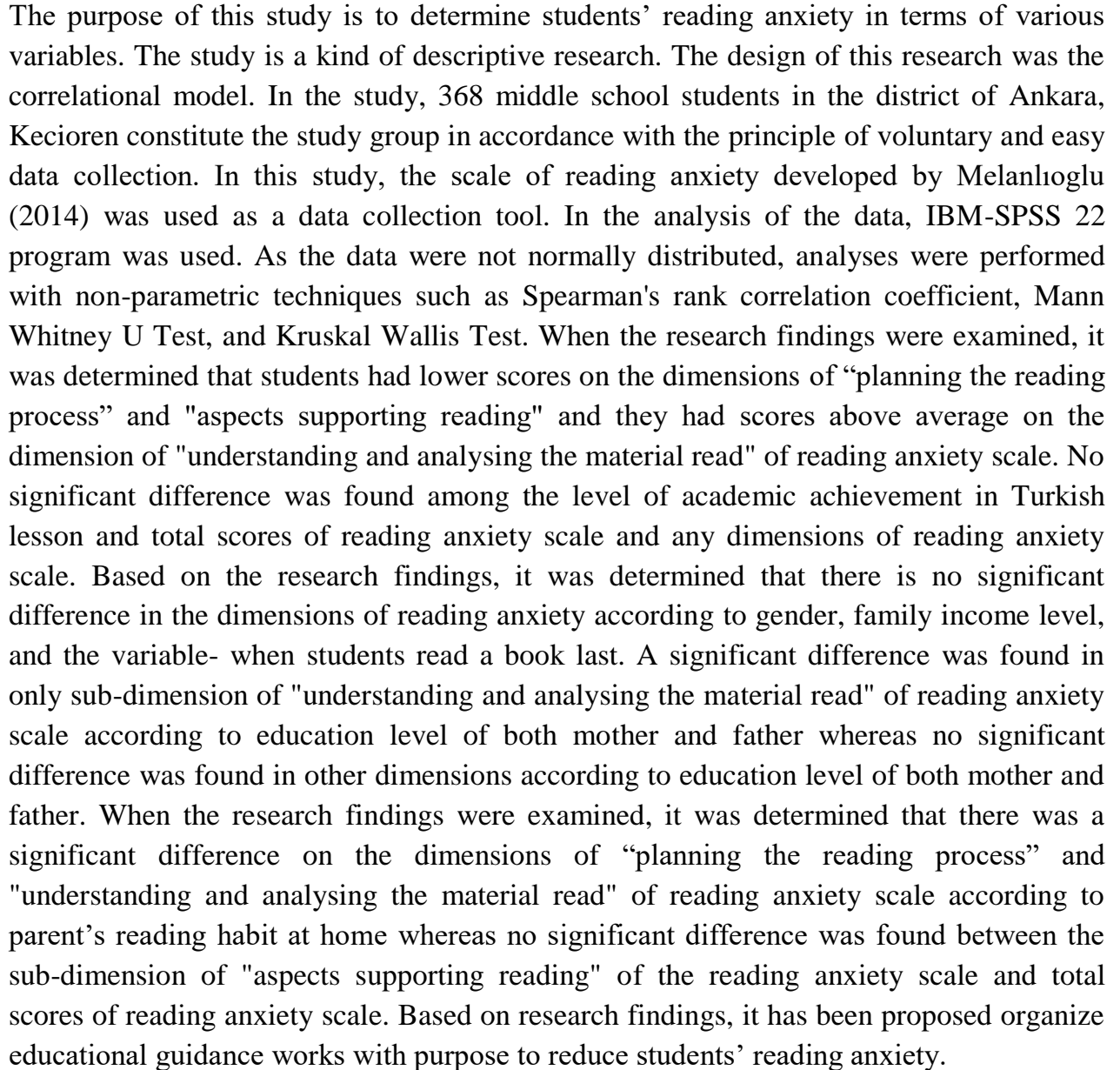 & $\begin{array}{l}\text { Keywords: Achievement, } \\
\text { Language teaching, Reading } \\
\text { anxiety } \\
\text { Article History: } \\
\text { Received: } 26 \text { February } 2018 \\
\text { Revised: } 12 \text { April } 2018 \\
\text { Accepted: } 27 \text { November } 2018 \\
\text { Article Type: Research Article }\end{array}$ \\
\hline
\end{tabular}




\section{Giriş}

Dil birincil iletişim kaynağıdır. Aynı zamanda, fikirlerimizi ve düşüncelerimizi başkalarıyla paylaştığımız bir yöntemdir. Aslında dil insanı diğer canlılardan ayıran en önemli özelliklerden birisidir. Bugün dünyada binlerce dil vardır. Farklı bölgelerde kendi halkı tarafından konuşulan yerel dillerin yanında ülkelerin kendilerine ait ulusal dilleri vardır. Etkili ve kullanışlı bir dil öğrenme ortamı yaratmak için ise dil öğrenme süreci, dil becerilerinin yardımıyla gerçekleştirilmektedir. Dil becerileri, iki gruba ayrılmaktadır. Bunlar, anlama ve anlatma ya da alıcı ve üretici beceriler olarak sınıflandırılırlar. Anlama veya alıcı dil becerilerini dinleme ve okuma becerileri oluştururken, anlatma veya üretme dil becerilerini ise konuşma ve yazma becerileri oluşturmaktadır.

Dil becerileri aynı zamanda işitsel ve grafiksel olarak da sınıflandırılmaktadırlar. Grafiksel beceriler, okuma ve yazmaya odaklanırken, işitsel beceriler, dinleme ve konuşma becerisi üzerinde durmaktadır. Grafiksel beceriler, insanların gördükleri veya duydukları söylemden anlam çıkarma şekilleridir. Örneğin öğrenciler TV izledikleri, roman okudukları, internette sörf yaptıkları ve haberleri dinledikleri veya bir şeyler hakkında konuştukları hallerde, dilin yeni biçimlerini geliştirmek için önceki bilgileri ve bir dizi alıcı becerileri kullanırlar (Al-Jawi, 2010). İşitsel beceriler ise dil öğrenme sürecinin halkasını oluşturan okuma ve yazma gibi grafiksel becerilerden önce gelmektedir (Bozorgian, 2012).

The Summer Institute of Linguistics-International (Uluslararası Summer Dilbilim Enstitüsü [SIL], 1999) kurumuna göre dört dil becerisi iki parametre açısından birbirleri ile ilişkilidir. Bunlar ise sözlü ve yazılı unsurlardan oluşan "iletişim biçimi”" ile mesajı alma veya üretmeyle ilgili "iletişim yönü” olarak açıklanmaktadır. Aslında her beceri, yeni öğrenilen dilin önemli bir bölümünü temsil etmektedir. Dinleme yoluyla, öğrencilerin dili anlamaları, sesler aracılığıyla sağlanmaktadır. Konuşma yoluyla, öğrenciler öğrendiklerini dili sözlü olarak pratiğe dökerek öğrenirler. Okuma aracılığıyla öğrenciler, gerçek bir metin üzerinde çalışırlar ve metinde yer alan yeni yapıları gözleyerek dili uygulama imkânı bulurlar. Yazma yoluyla öğrenciler öğrendikleri öğeleri yazarak öğrenirler. Bu beceriler içerinde yer alan okuma becerisi, öğrencilerin amaçlarını gerçekleştirmek için yazılı metinleri anlama, kullanma ve bunları yansıtma becerileri olarak tanımlanmaktadır. PISA'da, okuma yazma becerisi yalnızca bir metni anlama değil, kendi düşünce ve deneyimlerine dayanarak üzerinde derin bir düşünme sürecinin meydana geldiği kapasite ile ilişkili olarak değerlendirilir (Organisation for Economic Co-operation and Development [OECD], 2002).

Yurt içi ve yurt dışı literatürde okuma becerisine ilişkin olarak farklı tanımlamalar mevcuttur. Holloway'a (1999) göre okuma becerisi orta ve lise öğrencilerinin akademik başarıları için gerekli bir beceridir. Olson (1994) günümüz toplumunda okuma yazma bilmenin gerekli becerileri edinenlere avantaj sağladığından bu durumun bir önyargıyı da beraberinde getirdiğini iddia etmektedir. Aynı zamanda okuma becerisinin okur-yazar kurumlara erişim sağlamakta ve biliş veya düşünce süreçlerini etkilediğini belirtmektedir. Akyol (2015) ise okuma becerisini; ön bilgilerin kullanıldığı, yazar ve okuyucu arasındaki etkili iletişime dayalı, uygun bir yöntem ve amaç doğrultusunda, düzenli bir ortamda gerçekleştirilen anlam kurma süreci olarak tanımlanmaktadır. Okuma becerisi alanındaki başarı sadece eğitim sistemi içindeki diğer alanlarda başarı sağlamak için bir temel oluşturmakla kalmaz, aynı zamanda yetişkin yaşamın birçok alanına başarılı bir şekilde katılmanın da bir ön şartıdır (Cunningham ve Stanovich, 1998; Smith, Mikulecky, Kibby ve Dreher, 2000).

Anderson, Hiebert, Scott ve Wilkinson (1985) okumay1, yazılı metinlerden anlam çıkarma süreci olarak tanımlamışlardır. Aynı zamanda okuma becerisinin ilgili birçok bilgi kaynağının uyumunu gerektirdiğini vurgulamışlardır. Wixson, Peters, Weber ve Roeber'e (1987) göre okuma, okuyucunun var olan bilgisi, metin bilgisi ve okuma bağlamı unsurlarını içeren bir anlam yaratma sürecidir. Grabe (1991) ise okumayı, okuyucular ve okuma akıcılığıyla sonuçlanan metinler arasında etkileşimli bir süreç olarak tanımlamaktadır. Diğer bir ifadeyle, okuyucular, anlam çıkarmaya çalıştıkça metinlerle etkileşime girmektedirler. Pourhosein Gilakjani ve Ahmadi (2011), okumanın asıl amacının, yazarın okuyucunun almasını istediği doğru mesajı okuma metninden çıkarmak olduğunu belirtmiştir. Anderson, Hiebert, Scott ve Wilkinson'a (1985) göre, okuma temel bir yaşam becerisidir. Benzer şekilde, Akyol'a (2003)göre okuma, hayat boyu devam eden bir süreçtir. Badrawi (1992), okumanın bir süreçten oluştuğunu, okuma süreci sonucunda ise bu sürecin bir çıktısı olarak kabul edilen bir anlama ulaşıldığını ifade etmektedir. Aukerman (1981) okumanın algılayıcı ve bütünleştirici olmasının yanında hem bilişsel hem de duyuşsal süreçleri içerdiğini 
vurgulamaktadır. Sever'e (2004) göre, okuma anlık olarak gerçekleşmeyen, bilişsel, duyuşsal ve psikomotor boyutlardan oluşan çok boyutlu bir süreçtir. Piaget'nin (1974) ifade ettiği bilişsel açıdan öğrenme tanımı göz önünde bulundurulduğunda, okuma sürecinin öğrenme süreciyle bilişsel olarak birbirine paralel olduğu söylenebilir. Yalınkılıç (2017) ise, okuma becerisini, okuma sürecinde bilişsel, psikomotor ve duyuşsal becerilerin hayata geçirilerek yazar, metin ve okur temelinde gerçekleşen bir anlam oluşturma süreci olarak tanımlamaktadır. Razı (2007) ise, okuma becerisini dilsel, bilişsel ve duygusal süreçlerin bağlayıcısı olarak ele almaktadır. Kısacası, yukarıdaki tanımlardan da anlaşılacağı üzere, okuma becerisi bireylerin okuma süreci boyunca bilişsel, psikomotor ve duyuşsal becerilerini kullanmasını gerektiren anlam oluşturmaya dayalı çok boyutlu dinamik bir süreçtir.

Teknolojik gelişmeler, üst düzeyde eğitim ve bir alanda uzmanlaşmayı gerekli kılmaktadır. Bu durum aslında anlam temelli okumayla çok yakın bir bağın içerisindedir. 21. yüzyılda meydana gelen hızlı otomasyon, ulusal ve uluslararası alandaki rekabet, okuma becerisi gelişmemiş kişileri iş dünyasından ayıklamaktadır. Bir ülkede, okuma becerilerinin yeterince geliştirilmesi mevcut işleri elde etmede o ülkeyi kuvvetli bir yarışa girme olanağ1 sağlar. Aslında okuma becerisi günlük yaşantı açısından, iyi bir okur yazar olmak ve kişisel gelişim açısından son derece önemlidir (Akyol, 2015).

Okuma kaygısı ise dikkate alınması gereken okuma becerisinin duyuşsal unsurlardan birisini oluşturmaktadır. Öncelikle psikologların kaygı hakkında söylediklerine göz atıldığında kaygı ile ilgili olarak şunlar söylenebilir.

- Kaygı̈, ögrenmeyi engelleyen olumsuz bir duygudur.

- Korku; mevcut veya yakın tehditlere karşı bir tepkiyken, kaygı hayal veya uzak tehditlere karşı bir korku tepkisidir.

- Kaygı, gelecekteki tehditlere veya benlik saygısını tehdit eden bir çaresizlik duygusudur.

- Kaygı bozuklukları hem çocukluk çağında en yaygın olarak görülen bir durumdur hem de en erken ortaya çıkan bir rahatsızlıktır.

- Kaygı yoğun olduğu zaman, çocukların dikkat etme kabiliyeti zarar görür.

Okuma kaygısı ise, fiziksel ve bilişsel tepkiler içeren okuma hareketine yönelik belirli, durumsal bir fobi olarak tanımlanmaktadır (Zbornik, 2001, aktaran Jalango ve Hirsh, 2010). Okuma eylemi sürecinde kaygı ile ilgili durumla ilgili olarak, birey tarafından adrenalin hormonu salınımı ve terleme, ellerin titremesi, baş ağrısı, mide ağrısı, hızlı nefes alma, kalp çarpıntısı gibi fiziksel belirtiler ve gerginlik, ezici bir korku hissi, düşük benlik hissi, çaresiz duygular ve toplumsal aşağılamaya ilişkin bilişsel tepkiler gösterilmektedir.

Yurtiçi ve yurt dışında yapılan araştırmalar incelendiğinde yapılan çalışmalarda yoğunluklu olarak okuma kaygısının yabancı dil edinimi bağlamında ele alındığı (Brantmeier, 2005; Capan ve Karaca, 2013; Liu ve Hu, 2009; Lu ve Lui, 2015; MacIntyre ve Gardner, 1989; Mills, Pajares ve Herron, 2006; Park ve French, 2013; Pichette, 2009; Rajaba ve diğerleri, 2012; Saito, Horwitz ve Garza, 1999; Wu, 2011; Young, 1986; Zhao, Guo ve Dynia, 2013; Zoghi, 2012), ana dil olarak Türkçe öğretiminde ise okuma kaygısı ölçeğinin geliştirilmesi, (Altunkaya ve Erdem, 2016; Çeliktürk ve Yamaç, 2015; Melanlığlu, 2014), hükümlü öğrencilerde okuma kaygısı (Altunkaya, 2017), okuma kaygısının okuma tutumuna etkisi (Baki, 2017), üstbiliş strateji eğitiminin okuma kaygısına etkisi (Melanlıoğlu, 2014), okuma alışkanlığının akademik başarıya etkisine (Yılmaz, 2012) yönelik yapıldığı görülmektedir. Özellikle okuma kaygılarının çeşitli değişkenler açısından incelenmesi ile ilgili olarak ilkokul 4. sınıf düzeyinde sadece bir çalışmaya rastlanılmıştır (Yıldız ve Ceyhan, 2016). Yapılan çalı̧malarda ortaokulda öğrenim gören öğrencilerin okuma kaygılarının çeşitli değişkenler bağlamında incelenmesine yönelik herhangi bir araştırmaya rastlanılmamış olması bu araştırmayı önemli kılmış olup yapılan çalışmanın alanyazına katkı sağlayacağı inanılmaktadır.

$\mathrm{Bu}$ araştırmanın amacı Ankara ili, Keçiören ilçesinde ortaokulda öğrenim gören öğrencilerin okuma kaygılarının çeşitli değişkenler bağlamında incelenmesidir. Bu amaç doğrultusunda aşağıdaki sorulara cevap aranmıştır;

1. Öğrencilerin okuma kaygıları hangi düzeydedir?

2. Öğrencilerin Türkçe dersi akademik başarıları ile okuma kaygıları arasında anlamlı bir ilişki var mıdır?

3. Cinsiyete, anne eğitim düzeyi, baba eğitim düzeyi, aile gelir düzeyi, anne baba evde kitap okuma durumu, öğrencinin en son ne zaman kitap okuduğu göre öğrencilerin okuma kaygısı arasında anlamı farklı1ık var mıdır? 


\section{Yöntem}

Araştırma betimsel araştırma türlerinden ilişkisel tarama deseninde gerçekleştirilmiştir (Büyüköztürk ve diğerleri, 2014). Bu araştırmada öğrencilerin okuma kaygıları çeşitli değişkenler bakımından betimlenmeye Türkçe dersi başarısı ile ilişkisi incelenmeye çalışılmıştır.

\section{Araştırma Grubu}

Araştırmanın verileri Ankara Keçiören'de ortaokul düzeyinde öğrenim gören toplam 368 öğrenciden elde edilmiştir. $\mathrm{Bu}$ öğrenciler Keçiören ilçesinin merkezi ve kenar mahallelerinde yer alan üç ortaokulun öğrencisidir. Araştırma grubu oluşturulurken grubun, araştırmaya katılmaya gönüllü, ulaşılması, veri toplanması kolay olan öğrencilerden oluşmasına dikkat edilmiştir. Bu durum araştırmada amaçlı örneklem kullanılmasına neden olmuştur. Araştırma grubuyla ilgili bazı demografik özellikler Tablo 1'de özetlenmiştir.

Tablo 1. Araştırma grubunun demografik özellikleri

\begin{tabular}{llcc}
\hline & Değişken & Frekans (f) & Yüzde (\%) \\
\hline \multirow{2}{*}{ Cinsiyet } & Erkek & 143 & 38,9 \\
& Kız & 225 & 61,1 \\
\hline \multirow{3}{*}{ Sınıf } & 5.Sınıf & 139 & 37,8 \\
& 6.Sınıf & 101 & 27,4 \\
& 7.Sınıf & 73 & 19,8 \\
& 8.Sınıf & 55 & 14,9 \\
\hline \multirow{3}{*}{ Anne Eğitim Düzeyi } & İlkokul-Ortaokul & 177 & 48,1 \\
& Lise & 144 & 39,1 \\
& Önlisans ve üstü & 47 & 12,8 \\
\hline \multirow{3}{*}{ Baba Ĕ̈itim Düzeyi } & İlkokul-Ortaokul & 129 & 35,1 \\
& Lise & 155 & 42,1 \\
& Önlisans ve üstü & 84 & 22,8 \\
\hline \multirow{3}{*}{ Ailenizin Gelir Düzeyi } & 0-2000 TL & 168 & 45,7 \\
& 2001-4000 TL & 145 & 39,4 \\
& 4001 TL ve Üstü & 55 & 14,9 \\
\hline
\end{tabular}

\section{Veri Toplama Aracı ve Özellikleri}

Araştırmada Melanlığlu (2014) tarafından geliştirilmiş olan "Okuma Kaygısı Ölçeği (OKÖ)" kullanılmıştır. Ölçek okuma sürecini planlama, okumayı destekleyen unsurlar ve okuduğunu anlama ve çözümleme boyutlarında bilgi sunmaktadır. ÖKÖ likert türde geliştirilmiş bir ölçektir. Toplam 14 maddeden oluşmaktadır. Ölçeğin alt boyutlarına ilişkin Cronbach Alpha güvenirlik katsayıları .61 ile .83 arasında değişmektedir. Ölçeğin tümü için güvenirlik düzeyi .87 olarak hesaplanmıştır. Melanlıŏ̆lu OKÖ uyguladığı doğrulayıcı faktör analizi sonucunda uyum indeksleri sonuçlarını şöyle belirlemiştir: $\mathrm{X} 2 / \mathrm{sd}=1.36, \mathrm{CFI}=0.99, \mathrm{RMSEA}=0.034, \mathrm{SRMR}=0.045 . \mathrm{Bu}$ değerler alanyazına göre mükemmel uyum değerleri düzeyindedir.

\section{Verilerin Analizi}

368 ortaokul öğrencisinden OKÖ ile elde edilen veriler analiz edilirken, araştırma sorularına paralel olarak "İlişkisiz Örneklemler İçin T-Testi, ANOVA ve Pearson Momentler Çarpımı Korelasyon Katsayısı Testi" uygulanması düşünülmüştür. $\mathrm{Bu}$ testler parametrik testlerdir. Bu testlerin uygulanabilmesi için gerek OKÖ'nün üç alt boyutundan gerekse toplamından elde edilen verilere uygulanan "Kolmogorov-Smirnov Normal Dağılım Testi" sonucunda, verilerin normal dağılım göstermesi gerekmektedir (Büyüköztürk, 2013; Green ve Salkind, 2008; Kalayc1, 2005; Özdamar, 2013). Test sonuçları Tablo 2'de gösterilmiştir.

Tablo 2'de yer alan KS testi sonucu incelendiğinde OKÖ ve üç boyutlarından elde edilen verilerin KS test sonuçlarının anlamlı olduğu $(\mathrm{p}<.05)$ görülmektedir. Bu sonuç elde edilen puanların normal dağılım göstermediğini kanıtlamaktadır. Bu nedenle analizlerde nonparametrik teknikler kullanılmıştır. 
Tablo 2. Kolmogorov-Smirnov (KS) normal dağılım testi sonuçları

\begin{tabular}{lrc}
\hline \multicolumn{1}{c}{ Ölçek } & n & p \\
\hline Okuma Sürecini Planlama & 368 & 0,000 \\
\hline Okumayı Destekleyen Unsurlar & 368 & 0,000 \\
\hline Okuduğunu Anlama ve Çözümleme & 368 & 0,000 \\
\hline Okuma Kaygısı & 368 & 0,013 \\
\hline
\end{tabular}

\section{Öğrencilerin Okuma Kaygıları}

\section{Bulgular}

Araştırmada OKÖ kullanılmıştır. Ölçeğin üç alt boyutu bulunmaktadır. Bu alt boyutlardan katılımcıların aldıkları puanların betimsel istatistikleri tablo 3 ’te gösterilmiştir.

Tablo 3. OKÖ'ye ait betimsel istatistikler

\begin{tabular}{lcccccc}
\hline \multicolumn{1}{c}{ Ölçek } & $\mathbf{n}$ & $\bar{X}$ & Mod & S & Minimum & Maksimum \\
\hline Okuma Sürecini Planlama & 368 & 17,36 & 7 & 7,11 & 7 & 35 \\
\hline Okumayı Destekleyen Unsurlar & 368 & 6,53 & 3 & 3,29 & 3 & 15 \\
\hline Okuduğunu Anlama ve Çözümleme & 368 & 12,49 & 11 & 4,04 & 4 & 20 \\
\hline Okuma Kaygısı & 368 & 36,38 & 36 & 11,84 & 14 & 70 \\
\hline
\end{tabular}

Tablo 3 incelendiğinde katılımcıların okuma sürecini planlama ve okumayı destekleyen unsurlar alt boyutlarında düşük puanlara yığıldıkları (mod: 7 ve 3), okuduğunu anlama ve çözümleme boyutunda ise ortanın üzerinde puan aldıkları belirlenmiştir. Öğrencilerin orta düzeyde okuma kaygısı yaşadıkları yorumu yapılabilir.

\section{Türkçe Akademik Başarı ve Okuma Kaygısı İlişki}

Araştırmaya katılan öğrencilerin Türkçe dersi karne notları okul idaresinden alınmıştır. Türkçe dersi başarı durumu ile okuma kaygısı ölçeğinin ve alt boyutlarının arasındaki ilişki incelenmiştir. Veriler normal dağılım göstermediğinden bu inceleme "Spearman Brown Sıra Farkları Korelasyon Katsayısı" ile hesaplanmıştır. Sonuçlar tablo 4'te gösterilmiştir.

Tablo 4. OKÖ ile Türkçe dersi akademik başarı ilişkisi

\begin{tabular}{lrrc}
\hline \multicolumn{1}{c}{ Değişkenler } & $\mathbf{n}$ & $\mathbf{r}$ & $\mathbf{p}$ \\
\hline Türkçe Dersi Karne Notu*Okuma Sürecini Planlama & 368 & $-0,004$ & 0,936 \\
\hline Türkçe Dersi Karne Notu*Okumayı Destekleyen Unsurlar & 368 & $-0,050$ & 0,341 \\
\hline Türkçe Dersi Karne Notu*Okuduğunu Anlama ve Çözümleme & 368 & 0,075 & 0,151 \\
\hline Türkçe Dersi Karne Notu*Okuma Kaygısı & 368 & 0,017 & 0,746 \\
\hline
\end{tabular}

Tablo 4 incelendiğinde Türkçe akademik başarı düzeyi ile gerek okuma kaygısı ölçeğinin toplam puanı ve gerekse alt boyutlarının hiçbiri ile anlamlı bir ilişki olmadığı belirlenmiştir ( $\mathrm{p}>.05)$. Ayrıca ilişkiler çok düşük, sıfıra çok yakın düzeydedir. Türkçe dersi karne notu ile okuma sürecini planlama arasında negatif yönde, düşük düzeyde ve anlamlı olmayan; Türkçe dersi karne notu ile okumayı destekleyen unsurlar arasında negatif yönde, düşük düzeyde ve anlamlı olmayan; Türkçe dersi karne notu ile okuduğunu anlama ve çözümleme arasında pozitif yönde, düşük düzeyde ve anlamlı olmayan; Türkçe dersi karne notu ile okuma kaygısı arasında pozitif yönde, düşük düzeyde ve anlamlı olmayan bir ilişki belirlenmiştir.

\section{Cinsiyet ve Okuma Kaygısı}

Araştırmaya katılan öğrencilerin cinsiyetine göre okuma kaygılarında anlamlı farklılık olup olmadığı test edilmiştir. Bu test Mann Whitney U Test ile yapılmıştır. Sonuçlar Tablo 5 'te gösterilmiştir. 
Tablo 5. Cinsiyete göre OKÖ karşılaştırması

\begin{tabular}{|c|c|c|c|c|c|c|}
\hline Değişken & Cinsiyet & $\mathbf{n}$ & Mean Rank & Sum of Ranks & $\mathbf{U}$ & $\mathbf{p}$ \\
\hline Okuma Sürecini & Erkek & 143 & 182,22 & 26057,50 & \multirow{2}{*}{15761,500} & \multirow{2}{*}{0,743} \\
\hline Planlama & $\mathrm{K}_{1 \mathrm{Z}}$ & 225 & 185,95 & 41838,50 & & \\
\hline Okumayı & Erkek & 143 & 185,89 & 26582,50 & \multirow[b]{2}{*}{15888,500} & \multirow[b]{2}{*}{0,840} \\
\hline $\begin{array}{l}\text { Destekleyen } \\
\text { Unsurlar }\end{array}$ & Kiz & 225 & 183,62 & 41313,50 & & \\
\hline$\overline{\text { Okuduğunu }}$ & Erkek & 143 & 174,72 & 24984,50 & \multirow[b]{2}{*}{14688,500} & \multirow[b]{2}{*}{0,158} \\
\hline $\begin{array}{l}\text { Anlama ve } \\
\text { Çözümleme }\end{array}$ & $\mathrm{K}_{1 \mathrm{Z}}$ & 225 & 190,72 & 42911,50 & & \\
\hline Okuma Kaygısı & $\begin{array}{c}\text { Erkek } \\
\mathrm{K}_{1 \mathrm{z}}\end{array}$ & $\begin{array}{l}143 \\
225\end{array}$ & $\begin{array}{l}178,91 \\
188,06\end{array}$ & $\begin{array}{l}25583,50 \\
42312,50\end{array}$ & 15287,500 & 0,421 \\
\hline
\end{tabular}
belirlenmiştir.

Tablo 5. İncelendiğinde cinsiyete göre okuma kaygısının boyutlarında anlamlı farklılık olmadığı (p>.05)

\section{Anne Eğitim Düzeyi ve Okuma Kaygısı}

Araştırmaya katılan öğrencilerin annelerinin eğitim düzeyine göre okuma kaygısında anlamlı farklılık olup olmadığı test edilmiştir. Bu test Kruskal Wallis Test ile yapılmıştır. Sonuçlar Tablo 6’ da gösterilmiştir.

Tablo 6. Anne eğitim düzeyine göre OKÖ karşılaştırması

\begin{tabular}{|c|c|c|c|c|c|c|}
\hline Değişken & Anne Eğitim & $\mathbf{n}$ & Mean Rank & $X^{2}$ & sd & $\mathbf{p}$ \\
\hline \multirow{3}{*}{$\begin{array}{l}\text { Okuma Sürecini } \\
\text { Planlama }\end{array}$} & İlkokul-ortaokul & 177 & 178,73 & \multirow{3}{*}{1,022} & \multirow{3}{*}{2} & \multirow{3}{*}{0,600} \\
\hline & Lise & 144 & 189,29 & & & \\
\hline & Ön lisans ve üstü & 47 & 191,56 & & & \\
\hline Okumayı & İlkokul-ortaokul & 177 & 175,87 & \multirow{3}{*}{2,287} & \multirow{3}{*}{2} & \multirow{3}{*}{0,319} \\
\hline Destekleyen & Lise & 144 & 192,53 & & & \\
\hline Unsurlar & Ön lisans ve üstü & 47 & 192,41 & & & \\
\hline Okuduğunu & İlkokul-ortaokul & 177 & 170,10 & \multirow{3}{*}{9,371} & \multirow{3}{*}{2} & \multirow{3}{*}{0,009} \\
\hline Anlama ve & Lise & 144 & 190,14 & & & \\
\hline Çözümleme & Ön lisans ve üstü & 47 & 221,46 & & & \\
\hline \multirow{3}{*}{ Okuma Kaygısı } & İlkokul-ortaokul & 177 & 173,31 & \multirow{3}{*}{4,463} & \multirow{3}{*}{2} & \multirow{3}{*}{0,107} \\
\hline & Lise & 144 & 191,22 & & & \\
\hline & Ön lisans ve üstü & 47 & 206,04 & & & \\
\hline
\end{tabular}

Tablo 6 incelendiğinde anne eğitim düzeyine göre okuma kaygısı ölçeğinin sadece "okuduğunu anlama ve çözümleme" alt boyutunda anlamlı farklılık $(X 2=9,371, \mathrm{p}<.05)$ belirlenmiştir. Bu farklılığın hangi alt boyutlar arasında olduğunu belirleyebilmek için nonparametrik Dunn çoklu karşılaştırma testi uygulanmıştır. Annesi üniversite mezunu olan öğrenciler anlamlı biçimde okuduğunu anlama ve çözümlemede annesi ilkokul-ortaokul mezunu olanlardan daha yüksek puana sahiptirler. Okuma kaygısı ölçeğinin diğer boyutlarında anne eğitim düzeyine göre anlamlı farklılık belirlenmemiştir.

\section{Baba Eğitim Düzeyi ve Okuma Kaygısı}

Araştırmaya katılan öğrencilerin babalarının eğitim düzeyine göre okuma kaygısında anlamlı farklılık olup olmadığı test edilmiştir. Bu test Kruskal Wallis Test ile yapılmıştır. Sonuçlar Tablo 7'de gösterilmiştir. 
Tablo 7. Baba eğitim düzeyine göre OKÖ karşılaştırması

\begin{tabular}{|c|c|c|c|c|c|c|}
\hline Değişken & Baba Ĕğitim & $\mathbf{n}$ & Mean Rank & $X^{2}$ & sd & $\mathbf{p}$ \\
\hline \multirow{3}{*}{$\begin{array}{l}\text { Okuma Sürecini } \\
\text { Planlama }\end{array}$} & İlkokul-ortaokul & 129 & 175,33 & \multirow{3}{*}{1,987} & \multirow{3}{*}{2} & \multirow{3}{*}{0,370} \\
\hline & Lise & 155 & 193,05 & & & \\
\hline & Önlisans ve üstü & 84 & 182,81 & & & \\
\hline Okumayı & İlkokul-ortaokul & 129 & 183,39 & \multirow{3}{*}{0,056} & \multirow{3}{*}{2} & \multirow{3}{*}{0,972} \\
\hline Destekleyen & Lise & 155 & 184,17 & & & \\
\hline Unsurlar & Önlisans ve üstü & 84 & 186,81 & & & \\
\hline \multirow{3}{*}{$\begin{array}{l}\text { Okuduğunu Anlama } \\
\text { ve Çözümleme }\end{array}$} & İlkokul-ortaokul & 129 & 164,10 & \multirow{3}{*}{7,364} & \multirow{3}{*}{2} & \multirow{3}{*}{0,025} \\
\hline & Lise & 155 & 194,85 & & & \\
\hline & Önlisans ve üstü & 84 & 196,73 & & & \\
\hline \multirow{3}{*}{ Okuma Kaygısı } & İlkokul-ortaokul & 129 & 169,78 & \multirow{3}{*}{3,947} & \multirow{3}{*}{2} & \multirow{3}{*}{0,139} \\
\hline & Lise & 155 & 194,35 & & & \\
\hline & Önlisans ve üstü & 84 & 188,92 & & & \\
\hline
\end{tabular}

Tablo 7 incelendiğinde baba eğitim düzeyine göre okuma kaygısı ölçeğinin sadece "okuduğunu anlama ve çözümleme" alt boyutunda anlamlı farklılık $(X 2=7,364, \mathrm{p}<.05)$ belirlenmiştir. Bu farklılığın hangi alt boyutlar arasında olduğunu belirleyebilmek için nonparametrik Dunn çoklu karşılaştırma testi uygulanmıştır. Babası üniversite ve lise mezunu olan öğrenciler anlamlı biçimde okuduğunu anlama ve çözümlemede babası ilkokul-ortaokul mezunu olanlardan daha yüksek puana sahiptirler.

Okuma kaygısı ölçeğinin diğer boyutlarında baba eğitim düzeyine göre anlamlı farklılık belirlenmemiştir.

\section{Aile Gelir Düzeyi ve Okuma Kaygısı}

Araştırmaya katılan öğrencilerin aile gelir düzeyine göre okuma kaygısında anlamlı farklılık olup olmadığ 1 test edilmiştir. Bu test Kruskal Wallis Test ile yapılmıştır. Sonuçlar Tablo 8'de gösterilmiştir.

Tablo 8. Aile gelir düzeyine göre OKÖ karşılaştırması

\begin{tabular}{|c|c|c|c|c|c|c|}
\hline Değişken & Gelir Durumu & $\mathbf{N}$ & Mean Rank & $X^{2}$ & sd & $\mathbf{p}$ \\
\hline \multirow{3}{*}{$\begin{array}{l}\text { Okuma Sürecini } \\
\text { Planlama }\end{array}$} & $0-2000$ & 168 & 178,74 & \multirow{3}{*}{1,072} & \multirow{3}{*}{2} & \multirow{3}{*}{0,585} \\
\hline & $2001-4000$ & 145 & 187,47 & & & \\
\hline & 4001- & 55 & 194,26 & & & \\
\hline Okumayı & $0-2000$ & 168 & 184,61 & \multirow{3}{*}{0,000} & \multirow{3}{*}{2} & \multirow{3}{*}{1,000} \\
\hline Destekleyen & $2001-4000$ & 145 & 184,43 & & & \\
\hline Unsurlar & 4001- & 55 & 184,33 & & & \\
\hline \multirow{3}{*}{$\begin{array}{l}\text { Okuduğunu Anlama } \\
\text { ve Çözümleme }\end{array}$} & $0-2000$ & 168 & 174,33 & \multirow{3}{*}{3,693} & \multirow{3}{*}{2} & \multirow{3}{*}{0,158} \\
\hline & $2001-4000$ & 145 & 188,78 & & & \\
\hline & $4001-$ & 55 & 204,29 & & & \\
\hline \multirow{3}{*}{ Okuma Kaygısı } & $0-2000$ & 168 & 177,82 & \multirow{3}{*}{1,606} & \multirow{3}{*}{2} & \multirow{3}{*}{0,448} \\
\hline & $2001-4000$ & 145 & 187,24 & & & \\
\hline & 4001- & 55 & 197,68 & & & \\
\hline
\end{tabular}

Tablo 8 incelendiğinde aile gelir düzeyine göre okuma kaygısı ölçeğinin alt boyutlarından hiçbirinde anlamlı farklı1ık olmadığı (p>.05) belirlenmiştir.

\section{Anne Baba Kitap Okuma Durumu ve Okuma Kaygısı}

Araştırmaya katılan öğrencilerin anne babalarının evde kitap okuma durumuna göre okuma kaygılarında anlamlı farklılık olup olmadığ 1 test edilmiştir. Bu test Mann Whitney U Test ile yapılmıştır. Sonuçlar Tablo 9'da gösterilmiştir. 
Tablo 9. Anne babanın evde kitap okuma durumuna göre OKÖ karşılaştırması

\begin{tabular}{|c|c|c|c|c|c|c|}
\hline Değişken & $\begin{array}{c}\text { Kitap Okuma } \\
\text { Durumu }\end{array}$ & $\mathbf{n}$ & Mean Rank & Sum of Ranks & $\mathbf{U}$ & $\mathbf{p}$ \\
\hline Okuma Sürecini & Evet & 205 & 195,17 & 40009,50 & \multirow{2}{*}{14520,500} & \multirow{2}{*}{, 031} \\
\hline Planlama & Hayır & 163 & 171,08 & 27886,50 & & \\
\hline Okumayı & Evet & 205 & 177,17 & 36320,00 & \multirow[b]{2}{*}{15205,000} & \multirow[b]{2}{*}{,135 } \\
\hline $\begin{array}{l}\text { Destekleyen } \\
\text { Unsurlar }\end{array}$ & Hayır & 163 & 193,72 & 31576,00 & & \\
\hline Okuduğunu & Evet & 205 & 195,03 & 39981,50 & \multirow[b]{2}{*}{14548,500} & \multirow[b]{2}{*}{033} \\
\hline $\begin{array}{l}\text { Anlama ve } \\
\text { Çözümleme }\end{array}$ & Hayır & 163 & 171,25 & 27914,50 & & \\
\hline Okuma Kaygısı & $\begin{array}{l}\text { Evet } \\
\text { Hayır }\end{array}$ & $\begin{array}{l}205 \\
163\end{array}$ & $\begin{array}{l}193,60 \\
173,06\end{array}$ & $\begin{array}{l}39687,50 \\
28208,50\end{array}$ & 14842,500 & ,066 \\
\hline
\end{tabular}

Tablo 9 incelendiğinde anne babanın evde kitap okuma durumuna göre okuma sürecini planlama alt boyutunda anlamlı farklılık belirlenmiştir $(\mathrm{p}<.05)$. Bu farklılık anne babası evde kitap okuyanlar lehinedir. Anne babanın evde kitap okuma durumuna göre okuduğunu anlama ve çözümleme alt boyutunda anlamlı farklılık belirlenmiştir $(\mathrm{p}<.05)$. Bu farklılık anne babası evde kitap okuyanlar lehinedir. Anne babanın evde kitap okuma durumuna göre okumayı destekleyen unsurlar alt boyutu ile okuma kaygısı toplam puanlarında anlamlı farkl111k belirlenmemiştir ( $\mathrm{p}>.05)$.

\section{En Son Kitap Okuma Zamanı ve Okuma Kaygısı}

Araştırmaya katılan öğrencilerin en son ne zaman kitap okuduklarına göre okuma kaygısında anlamlı farklılık olup olmadığı test edilmiştir. Bu test Kruskal Wallis Test ile yapılmıştır. Sonuçlar Tablo 10’da gösterilmiştir.

Tablo 10. Öğrencilerin en son ne zaman kitap okuduğuna göre OKÖ karşılaştırması

\begin{tabular}{|c|c|c|c|c|c|c|}
\hline Değişken & Kitap Okuma & $\mathbf{N}$ & Mean Rank & $X^{2}$ & sd & $\mathbf{p}$ \\
\hline \multirow{4}{*}{$\begin{array}{l}\text { Okuma Sürecini } \\
\text { Planlama }\end{array}$} & Son bir hafta & 287 & 191,31 & \multirow{4}{*}{7,791} & \multirow{4}{*}{3} & \multirow{4}{*}{0,051} \\
\hline & Son bir ay & 58 & 171,60 & & & \\
\hline & Son bir y1l ve uz & 16 & 126,41 & & & \\
\hline & Hiç & 7 & 144,86 & & & \\
\hline \multirow{4}{*}{$\begin{array}{l}\text { Okumayı } \\
\text { Destekleyen } \\
\text { Unsurlar }\end{array}$} & Son bir hafta & 287 & 185,27 & \multirow{4}{*}{0,103} & \multirow{4}{*}{3} & \multirow{4}{*}{0,991} \\
\hline & Son bir ay & 58 & 182,19 & & & \\
\hline & Son bir y1l ve uz & 16 & 178,19 & & & \\
\hline & Hiç & 7 & 186,36 & & & \\
\hline \multirow{4}{*}{$\begin{array}{l}\text { Okuduğunu Anlama } \\
\text { ve Çözümleme }\end{array}$} & Son bir hafta & 287 & 187,14 & \multirow{4}{*}{2,654} & \multirow{4}{*}{3} & \multirow{4}{*}{0,448} \\
\hline & Son bir ay & 58 & 184,16 & & & \\
\hline & Son bir yil ve uz & 16 & 143,50 & & & \\
\hline & Hiç & 7 & 172,79 & & & \\
\hline \multirow{4}{*}{ Okuma Kaygisı } & Son bir hafta & 287 & 190,46 & \multirow{4}{*}{6,156} & \multirow{4}{*}{3} & \multirow{4}{*}{0,104} \\
\hline & Son bir ay & 58 & 173,16 & & & \\
\hline & Son bir y1l ve uz & 16 & 130,19 & & & \\
\hline & Hiç & 7 & 158,43 & & & \\
\hline
\end{tabular}

Tablo 10 incelendiğinde öğrencilerin en son ne zaman kitap okuduğuna göre okuma kaygısı ölçeğinin alt boyutlarından hiçbirinde anlamlı farklılık olmadığ $(\mathrm{p}>.05)$ belirlenmiştir.

\section{Tartışma, Sonuç ve Öneriler}

$\mathrm{Bu}$ araştırmada Ankara ili, Keçiören ilçesinde ortaokulda öğrenim gören öğrencilerin okuma kaygıları çeşitli değişkenler bağlamında incelenmiştir. Araştırma sonucunda elde edilen bulgular incelendiğinde öğrencilerin okuma kaygılarının okuma sürecini planlama ve okumayı destekleyen unsurlar boyutlarında düşük puanlara yığıldıkları, 
okuduğunu anlama ve çözümleme alt boyutunun ise ortanın üzerinde puan aldığı görülmektedir. Öğrencilerin okuma kaygılarının, okuma sürecini planlama ve okumayı destekleyen unsurlar boyutunda düşük; okuduğunu anlama ve çözümleme alt boyutunun ise ortanın üzerinde yığılım göstermesi, öğrencilerin okuma alışkanlıklarının yeterli olmaması ve okumaya yönelik farkındalıklarının düşük olmasından kaynaklanmış olabilir. Altunkaya ve Erdem (2016) Baki (2017) ve Melanlığlu (2014a) tarafından yapılan araştırmalarda da, araştırma öncesi öğrencilerin okuma kaygılarının orta düzeyde olduğu bulgusu araştırma bulgularımızla benzerlik göstermektedir.

Araştırma sonucunda elde edilen bulgular incelendiğinde öğrencilerin Türkçe dersi akademik başarı düzeyi ile okuma kaygısı ölçeğinin toplam puanı ve gerekse alt boyutlarının hiçbiri ile anlamlı bir ilişki olmadığı görülmektedir. Akademik başarıyla okuma kaygısı arasında anlamlı bir fark olmaması dikkat çekicidir. Akın (2016) tarafından yapılan araştırmada okuma alışkanlığı olan olmayan öğrencilerin ile Türkçe ders başarısı arasında bir farklılık bulunmamıştır. Bu bulgu araştırma sonuçlarımızla benzerlik göstermektedir. Yılmaz (2012) araştırmasında kitap okumayı seven öğrencilerin sevmeyen öğrencilere göre akademik başarılarının daha yüksek olduğunu tespit etmiştir.

Araştırma sonucunda elde edilen bulgular incelendiğinde cinsiyete göre okuma kaygısı ölçeğin genelinde ve alt boyutlarında anlamlı farklılık olmadığı görülmektedir. Yıldız ve Ceyhan (2016) tarafından yapılan araştırmanın bulguları araştırma sonuçlarımızı desteklemekle birlikte bazı araştırmalarda (Alisinanoğlu ve Ulutaş, 2003; Park ve French, 2013; Uçgun, 2016; Toros ve Tataroğlu, 2002) kız öğrencilerinin erkek öğrencilere göre daha çok okuma kaygısına sahip olduğu görülmektedir. Bunda toplumun farklı bölgelerinde kızlara biçilen sosyal rollerinde etkisi ve kadınların yüksek duygusal kırılganlıklarının erkekler tarafından baskılanmasının etkisi olabilir (Farooqi, Ghani ve Spielberger, 2012),

Araştırma sonucunda elde edilen bulgular incelendiğinde anne ve baba eğitim durumuna göre okuma kaygis1 ölçeğinin genelinde anne ve baba eğitim durumuna göre anlamlı bir fark bulunmamıştır. Ölçeğin alt boyutlarında ise sadece "okuduğunu anlama ve çözümleme" alt boyutunda anlamlı farklılıklar tespit edilmiştir. Annesi üniversite mezunu olan öğrenciler anlamlı biçimde okuduğunu anlama ve çözümlemede annesi ilkokul-ortaokul mezunu olanlardan daha yüksek puana sahip olduğu görülmektedir. Baba eğitim düzeyine göre ise okuma kaygısı ölçeğinin sadece "okuduğunu anlama ve çözümleme" alt boyutunda anlamlı farklılık belirlenmiştir. Babası üniversite ve lise mezunu olan öğrenciler anlamlı biçimde okuduğunu anlama ve çözümlemede babası ilkokul-ortaokul mezunu olanlardan daha yüksek puana sahiptirler. Araştırma bulgumuzu destekler şekilde Yıldız ve Ceyhan (2016) tarafından yapılan araştırmada da öğrencilerin okuma kaygısı ile anne ve baba eğitim düzeyleri arasında anlamlı bir fark bulunmamıştır. Uçgun (2016) yaptığı çalışmada öğrencilerin okuma kaygıları ile anne ve baba eğitim düzeyi arasında anlamlı bir fark olduğunu tespit etmiştir. İlkokul, ortaokul ve lise mezunu anne ve babaların olduğu öğrenciler ile üniversite mezunu anne ve babaların olduğu öğrenciler arasında olduğu tespit edilen bu fark, üniversite mezunu anne ve babaya sahip öğrencilerin aleyhinedir. Okuma kaygısı ve eğitim düzeyine ilişkin araştırmalar incelendiğinde anne baba eğitim düzeyi arttıkça okuma kaygılarının da azaldığı görülmektedir (Alisinanoğlu ve Ulutaş; 2003; Durkan ve Özen, 2018; Katrancı ve Kuşdemir; 2016, Kuşdemir, 2016; Özen ve Durkan, 2016; Yenilmez ve Özbey; 2006). Öğrencilerin eğitiminden birinci derecede sorumlu olan anne ve babaların eğitim düzeylerinin yüksek olması, çocuklarının eğitimiyle yakından ilgilenmeleri ve onları okuma konusunda doğru yönlendirmelerinde olumlu etki yapabilir.

Araştırma sonucunda elde edilen bulgular incelendiğinde aile gelir düzeyine göre okuma kaygısı ölçeği genel ve ölçeğin alt boyutlarından anlamlı farklılık olmadığı belirlenmiştir. İlkokul öğrencilerinin okuma kaygılarının aile gelir düzeyine göre incelendiği araştırma olmamakla birlikte araştırmalarda, araştırma sonuçlarımızdan farklı olarak ailelerin gelir düzeyinin okuma alışkanlığı kazanmalarında etkili faktörlerden olduğu belirlenmiştir. Kakırman Yıldız (2016) tarafından yapılan araştırmada ailenin sosyo-ekonomik durumunun iyi olmasını okuma ile ilgili doğru ve bilinçli kaynakların alınmasında etkili olduğu; Kesebir Toktar (2012) tarafından yapılan araştırmada ise aile gelir düzeyi yüksek öğrencilerin okuma alışkanlıklarının aile gelir düzeyi düşük öğrencilere göre daha yüksek olduğu belirlenmişti.

Araştırma sonucunda elde edilen bulgular incelendiğinde anne baba kitap okuma durumuna göre öğrencilerin okuma kaygılarında ölçeğin genelinde anlamlı bir farklılık bulunmamıştır. Ölçeğin alt boyutlarında okuma sürecini planlama ve okuduğunu anlama ve çözümleme alt boyutlarında anne ve babası evde kitap okuyan öğrenciler lehine anlamlı farklılık belirlenmiş̧ir. Bunda öğrencilerin ebeveynlerini rol model almalarının etkisi olmuş olabilir. Okumayı destekleyen unsurlar alt boyutu ile okuma kaygısı toplam puanlarında anlamlı farklılık belirlenmemiştir. Öğrencinin 
ebeveynini veya diğer aile bireylerini kitap okurken görmesi okuma konusunda öğrenciye önemli bir motivasyon kazandıracaktır. Araştırma bulgularımızı destekler şekilde Magno (2010) tarafından gerçekleştirilen araştırma sonuçlarına göre, ebeveynlerin okuma konusunda öğrencilere model olması ve geri bildirim sağlamasının, öğrencilerin okuma kaygılarının azalmasında etkili olduğu belirlenmiştir.

Araştırma sonucunda elde edilen bulgular incelendiğinde en son kitap okuma zamanına göre öğrencilerin okuma kaygılarında ölçeğin genelinde anlamlı bir farklılık bulunmamıştır. Uçgun (2016) tarafından yapılan çalışmada araştırma sonuçlarımıza benzer şekilde ortaokul öğrencilerinin okuma kaygıları ile son bir ay içinde okudukları kitap sayısı arasında anlamlı bir fark bulunmamıştır. Okuma kaygısı ile en son kitap okuma zamanı arasında farklı11k olmaması dikkat çekicidir. Araştırma bulgularımızın aksine Yıldız ve Ceyhan (2016) tarafından yapılan araştırmada dördüncü sınıf öğrencilerinin okuma kaygılarının, kitap okuma alışkanlıklarına göre anlamlı bir farklılık gösterdiği ve bu farkın her gün kitap okuyanların lehine olduğu belirlenmiştir. Bu farklılığın nedeni olarak öğrencilerin her gün kitap okumalarının, öğrencilerin kitap okuma konusunda özgüvenlerini artırması ve dolaylı olarak kaygılarını azalmasının etkili olduğu söylenebilir.

Araştırma bulgularına dayalı olarak öğrencilerin okuma kaygılarını azaltmaya yönelik deneysel araştırmaların yapılması, öğrencilere ve öğrenci ebeveynlerine yönelik okuma kaygısını azaltmaya yönelik eğitsel çalışmalar düzenlenmesi ve rehberlik yapılmasının konuya ve alana yeni bakış açıları kazandıracağı düşünülmektedir. 


\section{Extended Summary \\ Introduction}

Language is the primary source of communication. In addition, it is a method that we use to share our ideas and thoughts with others. In order to create an effective and useful language learning environment, language learning process is carried out with the help of language skills. Language skills are divided into two groups. They are classified as understanding and narrative or as receptive and productive skills. Listening and reading skills constitute understanding or receptive skills whereas speaking and writing skills constitute narrative or productive skills.

Language skills are also classified as auditory and graphical skills. Graphical skills focus on reading and writing skills whereas auditory skills focus on listening and speaking skills. In the literature, it is emphasized that auditory skills precede graphical skills such as reading and writing skills that form the ring of the language learning process. Through reading, students work on a real text and find an opportunity to practice the language by observing the new structures in the text. Through writing, students learn by writing the items they learn. Reading ability is defined as the ability of students to understand, use and reflect written texts in order to realize their goals.

Reading anxiety is one of the affective elements that needs to be taken into consideration. Reading anxiety can be defined as a specific, situational phobia for reading movement involving physical and cognitive responses. In the process of reading, an individual has some conditions related to anxiety.

\section{Objectives}

The purpose of this study is to determine students' reading anxiety in terms of various variables. For this purpose, the following questions were sought;

1. At what level is students' reading anxiety?

2. Is there a significant relationship between the students' academic success and their reading anxiety?

3. Is there a significant relationship between gender, mother's education level, father's education level, family income level, parents' reading status at home, and the variable- when students read a book last?

\section{Method}

The study is a kind of descriptive research. The design of this study was correlational model. In this study, it is tried to examine the students' reading anxiety in terms of various variables and their relation with the success of Turkish lesson. The data of the study were obtained from 368 students in secondary school in Ankara. In the study, "Reading Anxiety Scale (RAS)" that was developed before was used. "RAS" is a likert type scale. It consists of 14 items in total. As the data were not normally distributed, analyses were performed with non-parametric techniques such as Spearman's rank correlation coefficient, Mann Whitney U Test, and Kruskal Wallis Test.

\section{Findings}

When the research findings were examined, it was determined that students had lower scores on the dimensions of "planning the reading process" and "aspects supporting reading" and they had scores above average on the dimension of "understanding and analyzing the material read" of reading anxiety scale. No significant difference was found among the level of academic achievement in Turkish lessons and total scores of reading anxiety scale and any sub dimensions of reading anxiety scale ( $p>.05$ ). A significant difference was found only in the sub-dimension of "understanding and analyzing the material read" of reading anxiety scale according to education level of both mother $(\mathrm{X} 2=9,371, \mathrm{p}<.05)$ and father $(\mathrm{X} 2=7,364, \mathrm{p}<.05)$ whereas no significant difference was found in other dimensions according to education level of both mother and father. When the research findings were examined, it was determined that there was a significant difference on the dimensions of "planning the reading process" and "understanding and analyzing the material read" of reading anxiety scale according to parent's reading habit at home $(\mathrm{p}<.05)$. This difference is in favor of those whose parents read books at home. On the other hand, no significant difference was found in the dimensions of reading anxiety according to gender, family income level, and the variable- when students read a book last. 


\section{Discussion and Conclusion}

When the research findings were examined, it was determined that students had lower scores on the dimensions of "planning the reading process" and "aspects supporting reading" and they had scores above average on the dimension of "understanding and analyzing the material read" of reading anxiety scale.

Students' level of reading anxiety from different studies was found to be similar to our study findings. No significant difference was found among the level of academic achievement in Turkish lessons and total scores of reading anxiety scale and any sub-dimensions of reading anxiety scale.

When the findings of the study were examined, it was seen that there was no significant difference according to gender in overall and sub-dimensions of the scale. The findings of some studies from literature support our research results, but it was seen that female students had more reading anxiety than male students in some studies.

When the findings of the study were examined, it was determined that no significant difference was found on the overall of reading anxiety scale according to parent's reading habit at home. Some studies support our study by reaching a conclusion that there was no significant difference between the students' reading anxiety and their parents' education level, whereas some studies found that there was a significant difference between the students' reading anxiety and their mother and father's education level.

When the findings obtained from the study were examined, it was determined that there was no significant difference between the overall and sub-dimensions of the scale according to the family income level.

When the findings of the study were examined, no significant difference was found in the overall reading anxiety scale in terms of the variable- when students read a book last, which was supported by some studies.

Based on the findings of the study, it is thought that experimental studies that aim to reduce students' reading anxiety should be done and educational studies for students and parents that aim to reduce students' reading anxiety should be organized, which will provide new perspectives to the subject and field. 


\section{Kaynakça / References}

Akın, E. (2016). Ortaokul öğrencilerinin okuma alışkanlığı ve yazma tutumları ile Türkçe dersi akademik başarıları arasındaki ilişkinin incelenmesi. Akademik Bakış Dergisi, 54, 469-483.

Akyol, H. (2003). Türkçe ilkokuma ve yazma öğretimi. Gündüz Eğitim ve Yayıncılı, Ankara.

Akyol, H. (2015). Türkçe ögretim yöntemleri (15. baskı). Ankara: PegemA Yayıncılık.

Alisinanoğlu, F., \& Ulutaş, İ. (2003). Çocukların Kaygı Düzeyleri İle Annelerinin Kaygı Düzeyleri Arasındaki İlişkinin İncelenmesi. Eğitim ve Bilim, 28 (128), 65-71. Al-Jawi, F. D. (2010). Teaching the receptive skills. Retrieved June 17/2017 from http://uqu.edu.sa/files2/tiny_mce/plugins/filemanager/files/4281126/lectureof _Methodology_2/receptive_skills.pdf

Altunkaya, H. (2017). Açık öğretim ortaokulu öğrencisi hükümlü ve tutukluların okuma kaygıları. Türkiye Sosyal Araştırmalar Dergisi, 2,513-534.

Altunkaya, H., \& Erdem, İ. (2016). Yabancı dil olarak Türçe öğrenenlere yönelik okuma kaygısı ölçeğinin geliştirilmesi. S.Dilidüzgün (Ed.), Kuram ve uygulama bağlamında Türkçe öğretimi. Ankara: Anı Yayıncılı.

Alyousef, H. S. (2005). Teaching reading comprehension to Esl/Efl learners. The Reading Matrix, 5 (2), 143-154.

Anderson, R. C., Hiebert, E. H., Scott, J. A., \& Wilkinson, I. A. G. (1985). Becoming a nation of readers. Washington, D. C.: National Institute of Education.

Badrawi, N. (1992). The reading dilemma: meeting individual needs. English Teaching Forum, 30 (3) 31-35.

Baki, Y. (2017). Ortaokul öğrencilerinin okumaya ilişkin kaygı ve tutumlarının okuma alışkanlığı üzerindeki etkisi: bir yapısal eşitlik modellemesi. Ĕgitim ve Bilim, 42 (191), 371-395

Bozorgian, H. (2012). The relationship between listening and other language skills in International English Language Testing System. Theory and Practice in Language Studies, 2 (4), 657-663.

Brantmeier, C. (2005). Anxiety about L2 reading or L2 reading tasks? A study with advanced language learners. The Reading Matrix, 5(2), 67-85.

Büyüköztürk, Ş., Kılıç Çakmak, E., Akgün, Ö. E., Karadeniz, Ş. \& Demirel, F. (2014). Bilimsel araştırma yöntemleri. Ankara: Pegem Akademi

Büyüköztürk, Ş. (2013). Sosyal bilimler için veri analizi el kitabl. Ankara: Pegema Yayınları

Capan, S. A., \& Karaca, M. (2013). A comparative study of listening anxiety and reading anxiety. Procedia-Social and Behavioral Sciences, 70, 1360-1373.

Cunningham, A. E., \& Stanovich K. E. (1998). Early reading acquisition and its relation to reading experience and ability 10 years later. Developmental Psychology, 33 (6), 934-945.

Çeliktürk, Z., \& Yamaç, A. (2015). İlkokul ve ortaokul öğrencileri için okuma kaygısı ölçeğinin geliştirilmesi: geçerlik ve güvenirlik çalışması. İlköğretim Online, 14 (1), 97-107.

Durkan, E. ve Özen, F. (2018). İlkokul dördüncü sınıflarda görev yapan sınıf öğretmenlerinin Türkçe derslerinde öğrencilerinde üstbilişsel okuma stratejileri kullanmalarını sağlayan uygulamalarının değerlendirilmesi: Giresun ili örneği. Turkish Studies, 13 (4), 519-550

Farooq1, Y. N., Ghani, R., \& Spielberger, C. D. (2012). Gender differences in test anxiety and academic performance of medical students. International Journal of Psychology and Behavioral Sciences, 2 (2), 38-43.

Gilakjani, A. P., \& Ahmadi, S. M. (2011). The relationship between L2 reading comprehension and schema theory: A matter of text familiarity. International Journal of Information and Education Technology, 1(2), 142-149.

Green, S. B., \& Salkind, N. J. (2008). Using SPSS for Windows and Macintosh (Analyzing and Understanding Data-Fifth Edition). Pearson Prentice Hall. New Jersey

Holloway, J. H. (1999). Improving the reading skills of adolescents. Educational Leadership, 57 (2), 80-82. 
Jalongo, M. R., \& Hirsh, R. A. (2010). Understanding reading anxiety: New insights from neuroscience. Early Childhood Education Journal, 37 (6), 431-435.

Liu, M., \& Hu, Y. (2009). Reading anxiety in EFL classrooms: A case study. In Proceedings of the 3rd International Symposium on Teaching English at Tertiary Level (pp. 48-56). Hong Kong: Hong Kong Polytechnic University.

Magno, C. (2010). The effect of scaffolding on children's reading speed, reading anxiety, and reading proficiency. TESOL Journal, 3, 92-98.

Kakırman Yıldız, A. (2016). Okul öncesi dönem çocuklarının okuma alışkanlığı kazanmasında rol model olarak aile. Mavi Atlas, 7, 95-112. Doi: 10.18795/ma.94919.

Kalaycı, Ş. (2005). SPSS uygulamalı çok değişkenli istatistik teknikleri. Ankara: Asil Yayın Dağıtım.

Katrancı, M., \& Kuşdemir, Y. (2015). Öğretmen adaylarının konuşma kaygılarının incelenmesi: sözlü anlatım dersine yönelik bir uygulama. Dicle Üniversitesi Ziya Gökalp Ĕ̈itim Fakültesi Dergisi, 24 (2015), 415-445.

Kesebir Toktar, E. (2012). Edirne ili merkez ilçesinde bulunan ilköğretim 1. kademe öğrencilerinin okuma alışkanlıkları ve kütüphane kullanımları (Yayımlanmamış yüksek lisans tezi). Trakya Üniversitesi Sosyal Bilimler Enstitüsü, Edirne.

Liu, M., \& Hu, Y. (2009). Reading anxiety in EFL classrooms: A case study. In Proceedings of the 3rd International Symposium on Teaching English at Tertiary Level (pp. 48-56). Hong Kong: Hong Kong Polytechnic University.

Lu, Z., \& Lui, M. (2015). An investigation of Chinese university EFL learner's foreign language reading anxiety, reading strategy use and reading comprehension performance. Studies in Second Language Learning and Teaching SSLLT, 5 (1), $65-85$

MacIntyre, P. D., \& Gardner, R. C. (1989). Anxiety and second-language learning: Toward a theoretical clarification. Language learning, 39 (2), 251-275.

Melanlığlu, D. (2014). Okuma kaygısı ölçeğinin psikometrik özelliklerinin belirlenmesi. Eğitim ve Bilim Dergisi, 39, 176, 95105.

Melanlioğlu, D. (2014a). Üstbiliş strateji eğitiminin ortaokul öğrencilerinin okuma kaygılarına etkisi. Eğitim ve Bilim, 39 (176), p. 107-119

Mills, N., Pajares, F., \& Herron, C. (2006). A reevaluation of the role of anxiety: Self-efficacy, anxiety, and their relation to reading and listening proficiency. Foreign Language Annals, 39 (2), 276-295

OECD (2002). Reading for change - Performance and engagement across countries. Paris: OECD.

Olson, D. R. (1994). The world on paper. Cambridge: Cambridge University Press

Özdamar, K. (2013). Paket programlar ile istatistiksel veri analizi (9. Baskı). Eskişehir: Nisan Kitabevi.

Özen, F. ve Durkan, E. (2016). Üstbilişsel okuma stratejileri kullandırma ölçeğinin geliştirilmesi, bir geçerlilik ve güvenilirlik çalışması. Turkish Studies, 11(14), 565-586

Park, G., \& FrencH, B. (2013). Gender differences in the foreign language classroom anxiety scale. System, 41 (2), $462-471$

Piaget, J. (1974). To understand is invent. New York: Viking Press.

Rajaba A., Zarina, W., Zakariab W., Rahmanc, H.A. Hosnid, A.D., \& Hassanie, S. (2012). Reading anxiety among second language learners Procedia - Social and Behavioral Sciences, 66, 362-369.

Razı, S. (2007). Okuma Becerisi Öğretimi ve Değerlendirilmesi, Kriter Yayınlar, İstanbul.

Pichette, F. (2009). Second Language Anxiety and distance language learning. Foreign Language Annals, 42 (1), 77-93.

Saito, Y., Horwitz, E., \& Garza, J. (1999) Foreign Language Reading Anxiety. The Modern Language Journal, 83 (2), $202-218$. 
Sever, S. (2004). Türkçe Öğretimi ve Tam Öğrenme, Ankara, Anı Yayıncılık.

Smith, M. C., Mikulecky, L., Kibby, M.W., Dreher, M.J., \& Dole, J.A. (2000). What will be the demands of literacy in the workplace in the next millennium? Reading Research Quarterly, 35(3), 378-383.

Toros, F., \& Tataroğlu, C. (2002). Dikkat eksikliği ve hiperaktivite bozukluğu: sosyo-demografik özellikler, anksiyete ve depresyon düzeyleri. Çocuk ve Gençlik Ruh Sağlı̆̆ı Dergisi, 9 (1), 23-31.

The Summer Institute of Linguistics-International (1999). What is language?. https://www.sil.org/language-development sayfasından erişilmiştir.

Uçgun, D. (2016). Ortaokul öğrencilerinin okuma ve dinleme kaygıları arasındaki ilişkinin incelenmesi. Uluslararası Türkçe Edebiyat Kültür Eğitim Dergisi, 5 (4), 1958-1970

Wixson, K., Peters, C., Weber, E., \& Roeber, I. (1987). New directions in state wide reading assessment. The Reading Teacher, 40 (8), 749-755.

Wu, H. -J. (2011). Anxiety and reading comprehension performance in English as a foreign language. Asian EFL Journal, 13 (2), 273-306.

Yalınkılıç, K. (2017). Öğrencilerin okumaya karşı güdüleyici etmenlerle karşılaşma durumları ve okuma alışkanlıklarına ilişkin görünümleri. Researcher: Social Science Studies, 5(4), 423-434.

Yenilmez, K., \& Özbey, N. (2006). Özel okul ve devlet okulu öğrencilerinin matematik kaygı düzeyleri üzerine bir araştırma. Uludağ Üniversitesi Eğitim Fakültesi Dergisi, 19 (2), 431-448.

Yıldız, M., \& Ceyhan, S. (2016). İlkokul 4. sınıf öğrencilerinin okuma ve yazma kaygılarının çeşitli değişkenler açısından incelenmesi. International Periodical for the Languages, Literature and History of Turkish or Turkic, 11 (2), $1301-1316$.

Yılmaz, B. (2012). Okuma alışkanlığının okul başarısına etkisi: Ankara Keçiören Atapark İlköğretim Okulu öğrencileri üzerine bir araştırma. http://www.bby.hacettepe.edu.tr/akademik/bulentyilmaz/byilmaz1.pdf adresinden $28.07 .2017 \quad$ tarihinde alınmıştır.

Young, D. J. (1986). The relationship between anxiety and foreign language oral proficiency ratings. Foreign Language Annals, $19(5), 439-445$.

Zhao, A., Guo, Y., \& Dynia, J. (2013). Foreign language reading anxiety: Chinese as a foreign language in the United States. The Modern Language Journal, 97 (3), 764-778.

Zoghi, M. (2012). An instrument for EFL reading anxiety:inventory construction and preliminary validation. The Journal Of Asia Tefl, 9 (1), 31-56. 